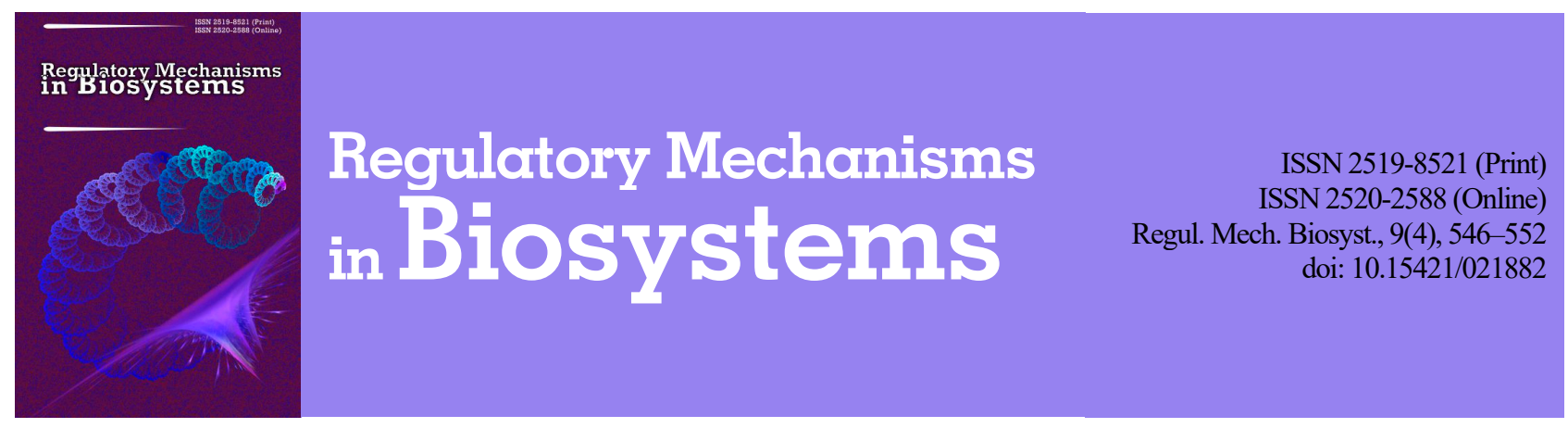

\title{
Prothrombotic states in women with infertility and psychosomatic disorders
}

\author{
A. V. Kaminskyi*, O. G. Boychuk**, T. V. Kolomiichchenko* \\ *Shupyk National Medical Academy of Postgraduate Education, Kyiv, Ukraine \\ **Ivano-Frankivsk National Medical University, Ivano-Frankivsk, Ukraine
}

Article info

Received 01.10.2018

Received in revised form 28.10.2018

Accepted 03.11.2018

Shupyk National Medical Academy of Postgraduate Education, Dorohozhytska st., 9 Kyiv, 04112, Ukraine.

Ivano-Frankivsk National Medical University, Halytska st. 2, Ivano-Frankivsk, 76018, Ukraine.

Tel.: +38-067-954-48-63

E-mail:tanyakolom@gmail.com
Kaminskyi, A. V., Boychuk, O. G., \& Kolomïchchenko, T. V. (2018). Prothrombotic states in women with infertility and psychosomatic disorders. Regulatory Mechanisms in Biosystems, 9(4), 546-552. doi:10.15421/021882

Failures of in vitro fertilization (IVF) may be associated with prothrombotic states, the circulation of antiphospholipid antibodies (APA). 93 women with infertility were screened: the first group - 32 women without severe psychosomatic disorders; the second group - 61 women with psychosomatic disorders. The control group consisted of 30 fertile women. We carried out measurements in the blood serum of the level of AFA to membrane phospholipids (phosphatidylethanolamine, phosphatidylserine, cardiolipinum), antibodies to $\beta_{2}$-glycoprotein $\left(\mathrm{I} \beta_{2}\right.$-GPI), hemostasis (platelet count, ADP-induced platelet aggregation index, fibrinogen concentration, prothrombin index, activated partial thromboplastin time - APTT, test for soluble fibrin-monomeric complexes, D-dimer), homocysteine, molecular genetic study of polymorphous variants for $\beta$-fibrinogen (C148T, 455GA) genes. The frequency of significant AFA titres in the group of women without psychosomatic disorders was $18.9 \%$, and in women with psychosomatic disorders $-44.3 \%$, the rate of $\beta_{2}$-GPI $9.6 \%$ in the first group versus $24.5 \%$ in the second group. Only in $11.5 \%$ of women in the second group elevated levels of APA were associated with $\beta_{2}$-GPI and/or one or more clinical criteria for antiphospholipid syndrome (APS). In patients with infertility and psychosomatic disorders, we found increased platelet aggregation in the context of relative thrombocytopenia, higher fibrinogen levels, soluble fibrin-monomeric complexes, and prolonged APTT with elevated D-dimer levels. Some patients had hyperhomocysteinemia. In patients with psychosomatic disorders, the frequency of the minor alleles of the locus C148T and 455GA of the $\beta$-fibrinogen gene was greater than $40 \%$ (25-30\% in first group). We distinguished factors that adversely affect the efficiency of IVF in the patients with psychosomatic disorders: elevation of APA; reduction in the number of thrombocites; growth of the ADP-induced aggregation index; extension of APTT; increase of fibrinogen, D-dimer; homocysteine; the presence of the minor allele of the T polymorphic locus C148T of the $\beta$-fibrinogen gene. The presence of prothrombotic states associated with APS should be taken into account when preparing for IVF and the appropriate correction should be made for them.

Keywords: in vitro fertilisation; antiphospholipid syndrome; hemostasis system; $\beta$-fibrinogen gene

\section{Introduction}

In the second decade of the new century, infertility remains a widespread common global condition. According to WHO, infertility is inability of a woman of reproductive age to become pregnant over a year of regular sexual life without contraception. Infertility is a complex medical-social problem of a global level, the extent of which affects the demographic parameters and has no tendency towards decrease. According to different assessments, infertility affects 8 to $12 \%$ of reproductive couples around the world, at the same time the indicators of infertility are much higher (up to 30\%) in some regions of the world, including Central and Eastern Europe (Mascarenhas et al., 2012).

There are various reasons for infertility, but most often, a complex impact of 2-5 factors is observed.

There is rising interest in the psychological factors behind infertility, which many researchers consider a psychosomatic disease (Boivin \& Gameiro, 2015; Lampe \& Schüßler, 2015). Infertility has deep social, economic, psychological and physical consequences, especially for women, significantly decreasing the quality of life. Experiencing infertility significantly worsens the psychological life of a person, which manifests in emotional reactions, psychological stress, sense of loss of control, impact on self-image, identity and social relations. Depressive symptoms occur in women with infertility twice as often as women with children. The impact of infertility is related to the factors such as depression, somaticzation and anxiety.
Assisted reproductive technologies (ART) are being actively developed, and are gradually become a routine procedure for solving the problem of producing children in case of infertility in marriage. Around 5 million children have been born thanks to ART, which equals $1 \%$ to $4 \%$ of all children born in the world (Ishihara et al., 2015). The main method of ART is extracorporeal fertilization (ECF). Most often, ECF is used in cases of obstruction or absence of uterine tubes; in cases of unclear reasons of infertility, decrease in total number of spermatozoids, disorders of their motility in men. However, despite initial successes, the efficiency of programmes of extracorporeal fertilization (ECF) has stagnated at the level of $20-35 \%$, that is most attempts remain unsuccessful, and these failures are repeated among some patients (Simon \& Laufer, 2012), which motivates further search for reasons for failure and the possibility of increasing the efficiency of ECF (Messerlian \& Gaskins, 2017). Some researchers have identified a relationship between recurdescent failures of ECF and psychological factors (Coughlan et al., 2014).

A number of authors consider that failures of ECF can be related to increased ability of blood coagulation, prothrombotic conditions and antiphospholipid antibodies circulation (APA) (Mashkova, 2015; Stuleva et al., 2015). The presence of one or more types of APA causes a threefold increase in the risk of failures of ECF (Sauer et al., 2010), though some authors deny such a relationship (Di Nisio et al., 2011).

Hypercoagulation syndrome is a relevant multi-disciplinary problem of the last decade, which is considered to be an inherited (primary) or obtained (secondary) condition of increased thrombogenesis in the arte- 
ries and/or veins. Disorder of hemostasis, which causes hypercoagulation syndrome, is manifested in different diseases in neurology, midwifery, rheumatology, surgery. Antiphospholipid syndrome (APLS) is the commonest form of hypercoagulation syndrome, which usually develops at a young age, among children and even newborns, 5 times more often in females than males. APLS is a symptom complex characterized by venous or arterial thrombosis or thrombocytopenia, which develop following the synthesis of antibodies to phospholipids.

The presence of APLS can be accompanied by different clinical situations. In "classic" APLS, recrudescent vessel thromboses (venous or arterial) develop. Another variant limited by the pregnancy pathology is midwifery APLS. Also, possible are asymptomatic APLS or development of non-thrombotic clinical manifestations of APLS (Negrini et al., 2017). In 1999, following a seminar of experts in Sapporo (Japan), provisional classification criteria of APLS were drawn up. In 2004 in Sydney (Australia) on the 11th International congress on APLS, the experts suggested some changes of the previous criteria such as including antibodies to $\beta_{2}$ glycoprotein I (Gómez-Puerta \& Cervera, 2014).

The diagnosis of determined antiphospholipid syndrome is made in the presence of one of the clinical criteria and one of the laboratory criteria in cases when the first laboratory examination was performed over 12 weeks since the clinical manifestations.

Clinical criteria.

1. Vascular thrombosis. One (or more) clinical episode of arterial, venous thrombosis or thrombosis of small vessels providing blood to any organ or tissue. Presence of thrombi must be proved by methods of visualization or Doppler test or proved pathohistologically, except for thrombosis of the superficial veins. During proving of the diagnosis using pathohistological investigation, thrombosis should be present without significant inflammatory processes in the vessel wall.

2. Pathology of pregnancy:

(a) one or more cases of undetermined death of a morphologically normal fetus in the 10th or later week of pregnancy, during presence of normal morphology of the fetus, recorded by ultrasound study or direct examination, or

(b) one or more early deliveries of a morphologically normal newborn before the 34th week of pregnancy as a result of (a) eclampsia or severe preeclampsia, determined according to the standard criteria, or (b) clear signs of fetoplacental insufficiency, or

(c) three or more unexplained successive spontaneous abortions before 10th week of pregnancy, at excluding anatomical or hormone disorders in the mother and chromosome anomalies in father and mother.

Patients who have one type of pregnancy pathology are strongly recommended to be separated into group $\mathrm{a}, \mathrm{b}$ or $\mathrm{c}$.

Laboratory criteria.

1. Anticardiolipid antibodies of IgG or IgM isotypes in the serum or blood plasma, present on average or high titer, found on 2 or more occasions during 12 weeks using the standardized method of immuneenzymic analysis.

2. Lupus anticoagulant in blood plasma, found on 2 or occasions during 12 weeks using the method which corresponds to the regulations of the International Society of Thrombosis and Hemostasis (Scientific Subcomission of Antioagulant of Lupus erythematosus / phospholipiddependent Antibodies).

3. Antibodies to $\beta_{2}$ glicoprotein I IgG and (or) IgM isotypes, found in blood serum or plasma on 2 or more occasions during 12 weeks using the standardized method of immune-enzymic analysis in correspondence with the recommended methods.

New models of quantitative assessment of risk of thromboses and midwifery processes in patients with APLS are in the process of development. Their main goal is detecting patients with higher possibility of development of new thromboses with a view to their for timely prevention. Apart from laboratory indicators, the global anti-phospholipid syndrome score (GAPSS) includes other variables such as cardio-vascular risk factors (Sciascia et al., 2013). It is expected that GAPSS will make it possible to provide quantitative assessment of risk of thrombosis and midwifery pathology in patients with APLS.

Disorders in the system of hemostasis can not only be one of the reasons for infertility, but also condition the successfulness of ART, maintenance of induced pregnancy, complication of its course, perinatal consequences. All these disorders can be conditioned by genetic vulnerability, particularly polymorphoses of fibrinogen $\beta$ gene, which are considered some of the primary markers of thrombophilia and to be related to premature birth and pre-eclampsia (Camilleri et al., 2004, Ticconi et al., 2011).

Fibrinogen-glycoprotein of acute phase, which is synthesized in the liver, consists of three polypeptides $\mathrm{A} \alpha, \mathrm{B} \beta$ and $\gamma$, which are encoded by alpha (FGA), beta (FGB) and gamma (FGG) genes, respectively (van 't Hooft et al., 1999). Fibrinogen is an important component of blood coagulation and the main factor which determines viscosity of blood and aggregation of thrombocytes. Under the influence of thrombin enzyme, this protein can transform into fibrin and form a thrombus. It simulates the function of endothelium and contributes to the proliferation of cells of smooth muscles and migration. Localization of fibrinogen beta gene (FGB) $-4 \mathrm{q} 28$.

A part of DNA in the regulatory area of FGB gene, where guanine (G) is changed by adenine (A) in the position 455, is marked as a genetic marker G (455) A. Presence of the change affects the intensity of synthesis of the fibrinogen enzyme. Frequency of occurrence of minor (A) allele in the European population, according to different authors, equals 5-10\%.

Mutation of 455A beta fibrinogen (FGB) is accompanied by increased expression of the gene, which causes heightened level of fibrinogen in blood and increases the probability of formation of thrombi, which can lead to thromboses and cardiovascular diseases and midwifery complications. The study of the group of healthy donors determined that the mutation of 455A causes heightened content of fibrinogen in blood (van 't Hooft et al., 1999).

Polymorphism of $156 \mathrm{C}>\mathrm{T}$ of FGB gene consists of nucleotide change of cytosine $(\mathrm{C})$ on thymine $(\mathrm{T})$ in the promotor area of the gene. Variant $\mathrm{T}$ is accompanied by increased expression of the gene, which causes increase in the content of fibrinogen in the blood and increases the probability of thrombus formation. Therefore, carriers of variant $\mathrm{T}$ have higher risk of diseases of the cardio-vascular system, disorders in placentation and other midwifery complications.

Presence of allele variants of the gene is a premorbid condition which can be the basis for development of reproductive disorders, assessment of the genetic status of a woman will allow one to predict the efficiency of ART programmes and perform preconception preparation for prevention of possible midwifery and perinatal complications.

Antiphospholipid antibodies affect all the stages of hemostasis system, damaging all its protection levels: endothelial barrier, function of natural anticoagulants, endogenic fibrinolysis, and activate the thrombocytic element of homeostasis and procoagulant factors. This process was named "triple punch". At the same time, by inhibiting the fibrinolysis due to inhibition of TFPI, the most important inhibitor of tissue factor, tissue activator of plasminogen and plasmin function, by damaging the function of all natural coagulants, including the system of protein $\mathrm{C}$, protein $\mathrm{S}$, antithrombin III, and by activating coagulation and the thrombocytic element of homeostasis, APLS is a powerful prothrombotic stimulus.

An important factor of reproductive and midwifery disorders is hyperhomocysteinemia which leads to disorders and activates endothelial cells, which significantly hightens the risk of thrombosis development (Lai \& Kan, 2015). On the other hand, hyperhomocysteinemia can be accompanied with the development of secondary autoimmune reactions and currently is considered one of causes of APLS (de Souza, 2007). Homocysteine induces the apoptosis of trophoblast cells and significantly decreases production of chorionic gonadotropin, which can be a cause of midwifery complications related to disorders in the implantation (Furness et al., 2013, Yajnik et al., 2014).

Also, thrombotic complications are the most serious, potentially lethal, complications of ART, which is related to the use of high doses of hormone preparations. For maximum increase in the number of viable embryos, transportation and cryopreservation in the process of IVF protocol, women are affected by high doses of exogenous gonadotropins, agonists or antagonists of $\mathrm{GnRH}$, which causes release of superphysiological levels of estradiol, associated with procoagulant changes in the 
hemostasis system, and is accompanied by increased thrombotic risk. Within two weeks, the estradiol concentration increases by over 100 times, and its level correlates with the level of fibrinogen, D-dimer and activated protein C. Stimulation of ovulation is accompanied by increases in some circulating coagulation factors: factor V, fibrinogen, Von Willebrand factor, thrombophilia markers, disorder in the function of endogenous anticoagulants, decrease in the levels of natural anticoagulants antithrombin III and protein S. Factually, in parallel, the process of chronic intravascular blood coagulation is activated. Women with excessive reactions to exogenous gonadotropins can develop ovarian hyperstimulation syndrome (OHSS) which is associated with deeper changes in the system of hemostasis and clear hypercoagulation (Chan, 2009; Kasum et al., 2014).

Presence of undiagnosed processes of activation of blood coagulation before ECF programmes are conducted is a risk factor of ovarian hyperstimulation syndrome and thromboses (Levy \& Lucidi, 2011; Rovaet et al., 2012). Risk of venous thromboembolia after ECF increases by $20-30$ times compared to the general population (Rao et al., 2005), which indicates the necessity of assessing such risk during preparation for ART and taking necessary preventive measures (Nelson, 2013; Sennström, 2017).

Presence of psychosomatic disorders in a woman with infertility can also be related to APLS, for currently antiphospholipid syndrome (APLS) is understood as a symptom complex which combines clinical signs and laboratory data: circulation of APA in combination with arterial and venous thromboses, syndrome of fetus loss, immune thrombocytopenia or neurological disorders (Negrini, 2017). Neurological disorders are among the most common manifestations of APLS. The first description of the disease, made by G. R. Hughes, included pathology of the nervous system. The possibility is foreseen that APA can directly connect with nervous tissues, thus causing disorders in their function. Although in the recent updated criteria of APLS classification (2006), the neurological manifestations cover only transient ischemic attacks and strokes, there are known various "non-criterial" neurologic disorders or manifestations: headache, migraine, bipolar disorder, myelopathy, dementia, chorea, epileptic seizures, multiple sclerosis, psychosis, cognitive disorders, Tourette syndrome, Parkinsonism, dystonia, transient global amnesia, disorders of eyesight etc. (Islam et al., 2016; Yelnik et al., 2016).

Therefore, the objective of our study was determining the role of antiphospholipid antibodies in the effectiveness of treating infertility using the methods of reproductive technologies on women with psychosomatic disorders.

\section{Materials and methods}

In the clinic of reproductive technologies of the Ukrainian National Institute of Reproductology of Shupyk National Academy of Postgraduate Education, 93 women with tubular-peritoneal factor of infertility were examined, who were prescribed the treatment of infertility using the methods of ART (main group). The control group comprised 30 fertile women with newborn children, and who had contacted the women' consultation service of the Kyiv Center of Reproductology and Perinatology for preconception preparation before planned parenthood.

All women were examined by therapist, psycho-neurologist. For the assessment of psychological and social status, we used a specially developed questionnaire, where the women answered the questions about the family condition, occupation, reproductive anamnesis, presence of bad habits.

The syndrome of vegetative dysfunction (SVD) was diagnosed using the A. M. Vein questionnaire (1998) with assessment of the vegetative symptoms expressed in points (11 parameters). For the quantitative assessment of SVD signs, expert assessment was performed by assigning a corresponding point (1 to 10$)$ in relation to the specific weight in the total of the SVD symptoms. If the total amount of the points reaches 15 and higher, the SVD is diagnosed.

Assessment of sleep disorders was made in accordance to the A. M. Vein Table which includes 6 questions, in accordance to which the respondent assesses the time of falling asleep, duration of sleep, night awakenings, dreams, quality of sleep, quality of awakening, by choo- sing one of the possible values in the point scale -1 to 5 , the norm was considered to be the total $>22$ points, light disorders are diagnosed at $18-22$ points, significant disorders $-<18$ points.

For the assessment of the level of stress, the Holmes and Rahe method was used, which includes 43 important events in the life over a past year, each of which corresponds to a particular point (11 to 100) depending on the extent of stressogenity. A total of less than 150 points shows an insignificant level of stress, 150 to 300 points - increased level of stress (50\% probability of occurrence of a particular psychosomatic disease); 300 points and higher - high level of stress ( $90 \%$ probability of such a disease).

For the assessment of the level of anxiety at a given moment (reactive or situational anxiety as a condition) and peculiarities of the anxiety (as stable characteristic of a person) the test was conducted using the Spielberg-Hanin method (1976).

For qualitative and quantitative assessment of depression, the Beck depression scale was used, which includes 21 groups of statements which reflect the peculiarities of the intellectual, emotional and body sphere of a person's psyche. The women interviewed in each group chose one statement which best corresponded to how they felt at the moment. Point 0 is put for each answer A, 1 point - for answer B, 2 for $\mathrm{C}$, and 3 - for $\mathrm{D}$. The total score allows assessment of the extent of depression: 0-4 points - no depression, 5-7 points - light depression; 8-15 points - mean level of depression; 16 and more points - high level of depression.

After the questioning of the women and consultation of a psychologist, the patients of the main group were divided into two groups in relation to presence and expression of psychosomatic disorders: first group - 32 women without clear psychosomatic disorders; second group -61 women with clear psychosomatic disorders.

The level of antiphospholipid antibodies (APA) to membrane phospholipids (phosphatidylethanolamine PE, phosphatidylserine PS, cardiolipin CL) in the serum of peripheral venous blood was determined using the method of immune-enzymic analysis with "Nobiwell" set of antibodies to two classes of immunoglobulins: Ig G and IgM ("Amersham Pharmacia Biotech", Great Britain). The APA level was considered increased if it equaled more than $20 \mathrm{U} / \mathrm{ml}$. Also, we determined antibodies to cofactor of APA of $\beta_{2}$-glycoprotein $\left(\beta_{2}\right.$-GPI) of two classes of immunglobulins: Ig G and IgM (increased level - over $20 \mathrm{U} / \mathrm{ml}$ ).

The examination of the hemostasis system (number of erythrocytes, index of ADP-induced aggregation of thrombocytes, concentration of fibrinogen, prothrombin index, activated partial thromboplastin time APTT, D-dimer) was made using biochemical analyzer. Also, we performed a test on soluble fibrin-monomer complexes.

The level of homocysteine was determined using the method of enzymic cyclic reaction with a Diasyid test (Germany) and a Respons 920 analyzer (Germany) according to the methods described by the manufacturer.

Molecular-genetic examination of polymorphic variants in relation to genes of $\beta$-fibrinogen (C148T, 455GA) was performed in the molecular-genetic laboratory of the State Institution "Reference-center of Molecular Diagnostics of the Ministry of Healthcare of Ukraine". For the genotyping, venous blood was collected in Monovette tubes in sterile conditions in amount of $2.7 \mathrm{ml}$ with dipotassium salt of ethylenediaminetetraacetic acid as a anticoagulant ("Sarstedt", Germany), frozen and maintained at $\mathrm{t}-20^{\circ} \mathrm{C}$. From the blood samples, selection of genome DNA was made using a commercial set "DNA-sorb-B" (in accordance with the manufacturer's manual). To determine C148T and 455GA of $\beta$-fibrinogen gene, we used the protocol with oligonucleotide primers with implementation of the PCR method followed by analysis of polymorphism of the length of restrictive fragments (PLRF). For this purpose, we amplified specific areas of the genes using a pair of specific primers ("Metabion", Germany). For the amplification, we took $3 \mu \mathrm{l}$ of the DNA and added them to a compound which contains $12.5 \mu \mathrm{l}$ of Dream Taq Green PCR of the working solution, by 20 pmol of primer 1 and 2 , the volume was increased to $25 \mu \mathrm{l}$ by adding deionized water. PCR was conducted in a FlexCycler BU thermocycler (Analytik Jena (Germany). The products of amplification of the fragments of the DNA of $\beta$-fibrinogen gene (C148T, 455GA) underwent hydrolytic separation 
using endonuclease of HindIII restriction. The condition of amplified and restricted fragments was analyzed using the horizontal electrophoresis in $2 \%$ agarous gel ( $160 \mathrm{~V}$ for 40 minutes). The obtained results were visualized using a transluminator and the patient's genotype was determined in relation to the molecular weight of the DNA fragments of the examined genes.

The results were statistically analyzed using Statistica 6.0 program packs (StatSoft Inc., USA). The statistical reliability of the difference between the selections and qualitative parameters which had normal distribution was assessed according to Student's t-test, for the parameters expressed in the shares, we used the criterion of Fisher's angle transformation, the differences were considered significant at $\mathrm{P}<0.05$. At the normal distribution law, the parameters are presented as mean arithmetic value, mean standard error $(\mathrm{x} \pm \mathrm{SE})$.

\section{Results}

Increased level of APA (over 10 GPL-U-ml for IgG and over 10 MPL-U-ml for IgM) was found only in $2(6.7 \%)$ women of the control group and in one third of the women with infertility (34 patients, $36.6 \%, \mathrm{P}<0.05$ ), i.e. over five time increase of this parameter was determined, which indicates the possibility of autoimmune and thrombovascular disorders which condition the risk of ART inefficiency and premature birth (Fig. 1). At the same time, in the range of the determined APA, the dominant part was anticardiolipid antibodies $(76.5 \%$ against $35.8 \%$ and $27.2 \%$ APA to PE and PS respectively).

At the same time, the antibodies to the cofactor APA $\beta_{2}$-GPI were found in $18(19.4 \%)$ patients and one (3.3\%) woman in the control group $(\mathrm{P}<0.05)$.

Analysis of determined APA depending on the presence and extent of manifestation of psychosomatic disorders indicated (Fig. 1) that the frequency of significant titers of APA in the 1st group equaled $18.9 \%$, and in women with psychosomatic disorders, it was more than twice as high, equaling $44.3 \%(\mathrm{P}<0.05)$. The frequency of finding $\beta_{2}$-GPI in the first group was $9.6 \%$ against $24.5 \%$ in the women in the second group.

An integrated analysis of anamnesis data indicated that only 7 $(11.5 \%)$ women of the second group had an increased level of APA combined with a significant level of $\beta_{2}$-GPI and/or one or several clinical criteria of APA (cases of instrumentally or morphologically proven vascular thrombosis, loss of morphologically normal fetus after 10 weeks of pregnancy, premature birth before the 34th week of pregnancy as a result of preeclampsia or clear placental insufficiency, three or more subsequent cases of spontaneous abortions before the 10th week of pregnancy without anatomic anomalies of the womb or chromosomal disorders). In these cases, APLS diagnosis was considered proven, for the other $23(37.7 \%)$ of women of the second group and all $7(18.9 \%)$ of the women of the first group, a clinically unproven increased APA level was determined as "doubtful APLS".
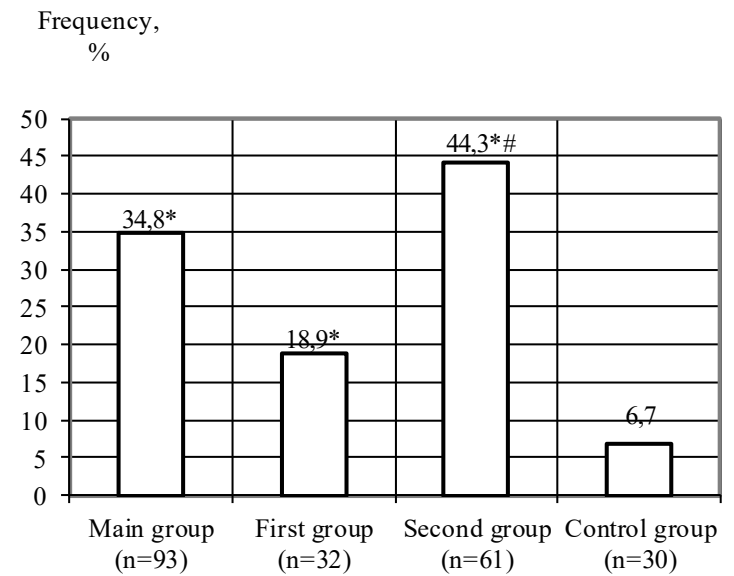

Fig. 1. Frequency of APA occurrence among the women with infertility depending on the presence and extent of psychosomatic disorders:

* - difference is statistically significant in relation to the parameter of women in the control group $(\mathrm{P}<0.05) ;{ }^{\#}$ - difference is statistically significant in relation to the parameter of women in the first group $(\mathrm{P}<0.05)$
The study of the hemostasis system (Table 1) of the patients with infertility and psychosomatic disorders revealed an increase in the aggregation of thrombocytes following relative thrombocytopenia (number of thrombocytes $231.4 \pm 15.5$ against $278.2 \pm 17.4$ and $341.3 \pm 18.4$ $10^{9} / 1$ in women of the first and control group, $\mathrm{P}<0.05$ ), and also, compared to the first group and in the control, significantly higher level of fibrinogen, soluble fibrin-monomer complexes $(8.4 \pm 1.2$ against $4.8 \pm 0.76$ and $3.7 \pm 0.32 \mathrm{mg} / \mathrm{ml}$ respectively, $\mathrm{P}<0.05)$, significantly extended APTT (to $34.9 \pm 1.2 \mathrm{~s}$ relatively $29.2 \pm 1.0$ and $26.3 \pm 1.2 \mathrm{~s}$ in the women of the 1 st and the control groups, $\mathrm{P}<0.05$ ) at significantly high level of D-dimer $(328.1 \pm 37.6$ in relation to $186.2 \pm 15.4$ and $158.3 \pm 18.4 \mathrm{ng} / \mathrm{ml}, \mathrm{P}<0.05)$. Such changes indicate certain vulnerability to hypercoagulation and thrombus formation and often are often associated with APLS. At the same time, there was recorded hyperhomocysteinemia among some of the patients from this group: mean value of concentration of the parameter equaled $10.5 \pm 0.36 \mu \mathrm{mol} / \mathrm{l}$ against $5.7 \pm 0.32$ and $5.0 \pm 0.24 \mu \mathrm{mol} / \mathrm{l}$ in the first and the control groups $(\mathrm{P}<0.05)$, which indicates the possibility of damaging endothelium of the vessel and is associated with APLS.

\section{Table 1}

Parameters of the hemostasis system and the level of homocysteine among the women with infertility $(x \pm S E)$

\begin{tabular}{lccc}
\hline & \multicolumn{3}{c}{ Group of women } \\
\cline { 2 - 4 } \multicolumn{1}{c}{ Parameter } & $\begin{array}{c}\text { first group (wo- } \\
\text { men with infer- } \\
\text { tility without } \\
\text { psychosomatic } \\
\text { disorders, } \mathrm{n}=32)\end{array}$ & $\begin{array}{c}\text { second group } \\
\text { (women with } \\
\text { infertility and } \\
\text { psychosomatic } \\
\text { disorders, } \mathrm{n}=61)\end{array}$ & $\begin{array}{c}\text { control group } \\
\text { (fertile } \\
\text { women, } \\
\mathrm{n}=30 \text { ) }\end{array}$ \\
\hline Number of & $(278.2 \pm 17.4)^{*}$ & $(231.4 \pm 15.5)^{*} \# 3$ & $341.3 \pm 18.4$ \\
thrombocytes, $10^{9} / 1$ & & & \\
Index of ATP-induced & $48.3 \pm 6.2$ & $(58.8 \pm 4.6)^{*}$ & $39.7 \pm-6.8$ \\
aggregation, \% & $3.0 \pm 0.21$ & $(4.2 \pm 0.26)^{*} \#$ & $2.8 \pm 0.40$ \\
Fibrinogen, g/d & $92.2 \pm 8.5$ & $107.4 \pm 13.6$ & $85.1 \pm 6.7$ \\
Prothrombin index, \% & $29.2 \pm 1.0$ & $(34.9 \pm 1.2)^{*} \#$ & $26.3 \pm 1.2$ \\
APTT, s & $4.8 \pm 0.76$ & $(8.4 \pm 1.2)^{*} \#$ & $3.7 \pm 0.32$ \\
SFMC-test, mg/ml & $186.2 \pm 15.4$ & $(328.1 \pm 37.6)^{*} \#$ & $158.3 \pm 18.4$ \\
D-dimer, ng/ml & $5.7 \pm 0.32$ & $(10.5 \pm 0.36)^{*} \#$ & $5.0 \pm 0.24$ \\
Homocysteine, $\mu \mathrm{mol} / 1$ & & &
\end{tabular}

Notes: ${ }^{*}$ - difference is significant in relation to the parameter of women of the control group $(\mathrm{P}<0.05) ;{ }^{\#}-$ difference is significant in relation to the parameter of women of the first group $(\mathrm{P}<0.05)$.

According to the obtained data on the women with infertility and psychosomatic disorders, we determined higher frequency of pathological polymorphisms of C148T gene of $\beta$-fibrinogen (Fig. 2).

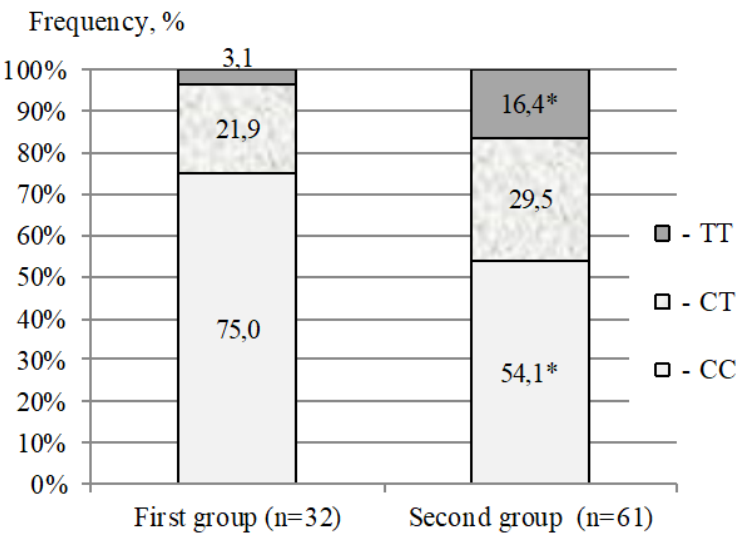

Fig. 2. Frequency of genotypes of polymorphism of C148T of $\beta$-fibrinogen gene: ${ }^{*}$ - difference is significant in relation to the parameter of the women from the first group $(\mathrm{P}<0.05)$

The normal variant of polymorphism in homozygous form CC occurred in the half $(54.1 \%)$ of the examined patients against $75.0 \%$ of the women with infertility without psychosomatic signs $(\mathrm{P}<0.05)$. The heterozygous form of polymorphism of CT was found in $21.9 \%$ of the women from the first group and one third $(29.5 \%)$ of the women from the second group. The mutant variant of polymorphism related to 
increase of the risk of thromboses and other pathologic conditions was found in homozygous form only in $1(3.7 \%)$ woman of the first group, and in 10 women in the second group, which equaled $16.4 \%(\mathrm{P}<0.05)$.

After conducting a study on the distribution of frequencies of the variants of genotypes in relation to 455GA polymorphism of $\beta$-fibrinogen gene among the women with infertility and liver disorders, we determined a certain decrease in the frequency of the protective allele $G$ and increase in the frequency of allele A which is responsible for the risk of development of thromboses and midwifery complications (Fig. 3) mostly due to the development of the heterozygous form (GA), the percentage of the carriers of which in the first group equaled $31.3 \%$. The homozygous variant AA, quite rare in the general population, was observed in $9.8 \%$ women of the second group.

Frequency, \%

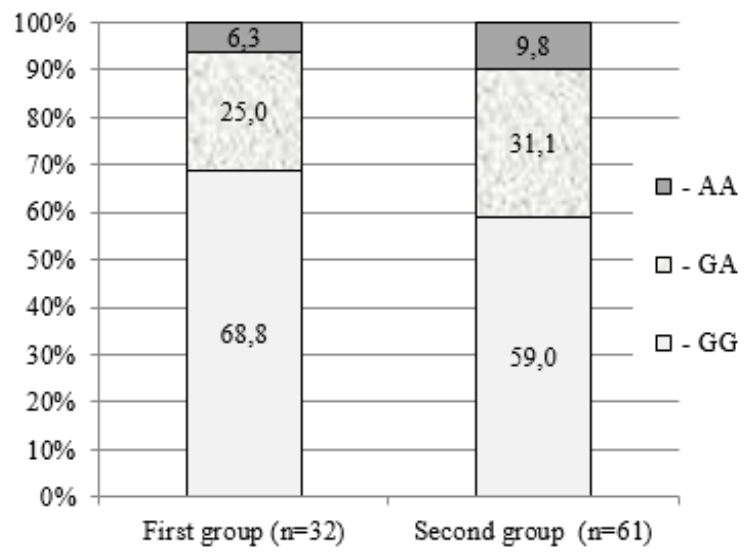

Fig. 3. The frequency of genotypes of $-455 \mathrm{GA}$ polymorphism of $\beta$-fibrinogen in the studied groups

Thus, our genetic study on the polymorph loci of C148T and 455GA of $\beta$-fibrinogen gene, which are associated with APLS and reproductive disorders of women, determined that in the group of women with infertility and psychosomatic disorders, the frequency of the minor alleles of these loci was within the figures for the general population, known from the literature sources (16-29\%), whereas in the patients with psychosomatic disorders it was over $40 \%$, therefore the frequency of minor allele $\mathrm{T}$ of polymorphic locus $\mathrm{C} 148 \mathrm{~T}$ equaled $45.9 \%$ against $25.0 \%$ among the women of the first group $(\mathrm{P}<0.05)$.

Table 2

Frequency of mutant alleles of polymorphic loci of $\beta$-fibrinogen gene among the women with infertility

\begin{tabular}{lcccc}
\hline & \multicolumn{4}{c}{ Group of women } \\
\cline { 2 - 5 } Parameter & $\begin{array}{c}\text { the first group (women with } \\
\text { infertility without psycho- } \\
\text { somatic disorders, } n=32)\end{array}$ & $\begin{array}{c}\text { the second group (women } \\
\text { with infertility and psycho- } \\
\text { somatic diseases, } n=61 \text { ) }\end{array}$ \\
\cline { 2 - 5 } & $\begin{array}{c}\text { number of } \\
\text { patients }\end{array}$ & $\%$ & $\begin{array}{c}\text { number of } \\
\text { patients }\end{array}$ & $\%$ \\
\hline $\begin{array}{l}\text { Minor allele T of } \\
\text { polymorphic locus C148T } \\
\begin{array}{l}\text { Minor allele A of poly- } \\
\text { morphic locus 455GA }\end{array}\end{array}$ & 8 & 25.0 & 28 & $45.9^{*}$ \\
\hline
\end{tabular}

Note: *-difference is significant in relation to the women of first group $(\mathrm{P}<0.05)$.

Analysis of the effectiveness of using ART on the patients of the examined groups revealed the following: pregnancy occurred almost in half of the women of the first group (46.8\%) and only in $14(23.0 \%)$ patients with psychosomatic disorders $(\mathrm{P}<0.05)$, which can be conditioned by the high frequency of their determined prothrombotic parameters associated with APLS and which can be used as predicting risk factors of ART inefficiency (Fig. 4):

- increase in the level of APA (odds ratio $\mathrm{OR}=2.4$; confidence interval CI 0.7-8.7, P > 0.05);

- decrease in the number of thrombocytes $(\mathrm{OR}=3.1 ; \mathrm{CI} 0.4-26.7, \mathrm{P}>0.05)$; - increase in the index of ATP-induced aggregations $(\mathrm{OR}=2.8$; $\mathrm{CI} 0.6$ 14.2, $\mathrm{P}>0.05)$;
- increase in the level of fibrinogen $(\mathrm{OR}=3.4 ; \mathrm{CI} 0.7-17.0, \mathrm{P}>0.05)$;

- prolongation of APTT $(\mathrm{OR}=3.1 ; \mathrm{CI}, 0.6-15.6, \mathrm{P}>0.05)$;

- increase in the level of D-dimer $(\mathrm{OR}=1.3$; CI $0.3-5.3, \mathrm{P}>0.05)$;

- increase in the level of homocysteine $(\mathrm{OR}=2.8 ; \mathrm{CI} 0.6-14.2, \mathrm{P}>0.05)$;

- presence of minor allele $\mathrm{T}$ of polymorphic locus $\mathrm{C} 148 \mathrm{~T}$ of $\beta$-fibrinogen gene $(\mathrm{OR}=4.2$; $\mathrm{CI} 1.0-16.9, \mathrm{P}<0.05)$.

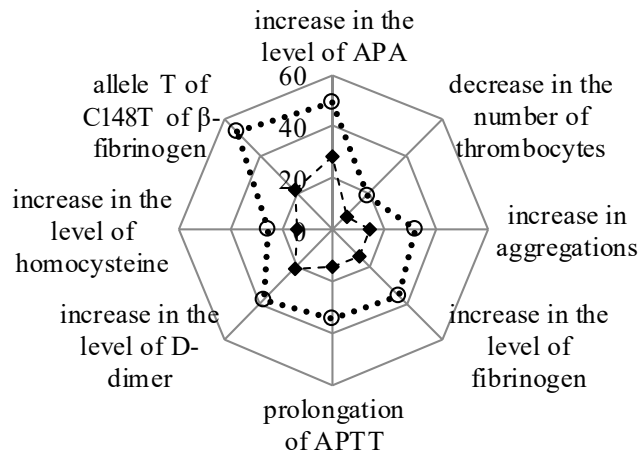

$$
-\cdots-- \text { ART effecttive }(\mathrm{n}=14)
$$$$
\cdots \cdots \text { ART ineffecttive }(\mathrm{n}=47)
$$

Fig. 4. Frequency of the factors associated with inefficiency of ART among the women with infertility and psychosomatic disorders $(\%)$

As we see from the data of risk and calculation of the odds ratio, among the analyzed factors, the most significant effect on the ART efficiency among the women with infertility and psychosomatic disorders belongs to the genetic conditionality - presence of minor allele $\mathrm{T}$ of polymorphic locus $\mathrm{C} 148 \mathrm{~T}$ of $\beta$-fibrinogen gene $(\mathrm{OR}=4.2 ; \mathrm{CI} 1.0-16.9, \mathrm{P}<0.05)$.

\section{Discussion}

We determined a more than five times increase in the frequency of finding significant titers of APA among the women with infertility, which indicates the possibility of autoimmune and thrombovascular disorders, which condition the risk of ART inefficiency and premature birth, which corresponds to the results of our studies (Sauer et al., 2010; Mashkova, 2015; Stuleva et al., 2015; Saccone et al., 2017; Song et al., 2017).

Analysis of manifestations of APA depending on the presence and manifestation of psychosomatic disorders indicated that the frequency of significant APA titers in patients with infertility and psychosomatic disorders was two times higher and equaled $44.3 \%$ against $18.9 \%(\mathrm{P}<$ 0.05 ). We found no similar data in the available literature, but such result can be explained by close relationship with various somatic pathology, particularly endocrine and cardiovascular pathology (Mehdi et al., 2011; da Silva et al., 2014).

An integrated analysis of anamnesis data showed that only $11.5 \%$ of those women had the APA level combined with one or several clinical APLS criteria and/or high level of antibodies to cofactor APA $\beta_{2}$-GPI. In such cases, the APLS diagnosis is considered proven (Chighizola et al., 2015). In $18.9 \%$ of the women, a clinically unproven level of APA is defined by the term "doubtful APLS", but the authors have demonstrated (Chernyshov et al., 2011) that such cases concern "cofactor antiphospholipid antibodies" associated with heightened risk of typical reproductive and midwifery complications. Such changes indicate certain immune-regulatory disorders and risk of autoimmune changes in future.

The study of the system of hemostasis revealed that the patients with infertility and psychosomatic disorders have a certain predisposition to hypercoagulation and thrombus formation, which is associated with APLS (Masliah-Planchon \& Darnige, 2012; Bao et al., 2017; Fabris et al., 2017). At the same time, some of the patients of this group were observed to have hyperhomocysteinemia which indicates possible damage to the endothelium of the vessels (Lai \& Kan, 2015) and is also associated with APLS (de Souza, 2007).

In the course of the study of the polymorph loci C148T and 455GA of $\beta$-fibrinogen gene, which according a number of researchers are related 
to APLS and reproductive disorders of women (Aléssio et al., 2008; JeddiTehrani et al., 2011; Tatarchuk et al., 2015), we determined that the group of women with infertility without psychosomatic disorders had a frequency of minor allele of these loci within the values reported in the literature sources (16-29\%) (Rupert et al., 1999; Madjunkova et al., 2012; Oszajca et al., 2012), whereas in the patients with psychosomatic disorders it exceeded $40 \%$.

After the analysis of odds ratio of the prothrombotic parameters we studied, we demonstrated their impact on the effectiveness of ART among women with infertility and psychosoamtic disorders, which coincides with the data of other researchers, which, however, did not consider the presence of psychosomatic disorders (Sauer et al., 2010; Mashkova, 2015; Stuleva et al., 2015). The most significant among the analyzed parameters, according to our data, is genetic conditionality - presence of minor allele $\mathrm{T}$ and polymorph locus $\mathrm{C} 148 \mathrm{~T}$ of $\beta$-fibrinogen gene $(\mathrm{OR}=$ 4.2; CI 1.0-16.9, $\mathrm{P}<0.05)$.

\section{Conclusions}

The women with infertility and psychosomatic disorders were characterized by a high frequency of increase in the level of antiphospholipid antibodies, antibodies to $\beta_{2}$-glycoprotein and other prothrombotic conditions (changes in the system of hemostasis towards thrombus formation and increase in coagulation potential, hyperhomocystenemia, carrying mutant alleles of polymorphic loci of $\beta$-fibrinogen gene) associated with antiphospholipid syndrome. There the factors were distinguished which negatively affect the effectiveness of the use of assistive reproductive technologies on the patients with psychosomatic disorders: increase in APA level $(\mathrm{OR}=2.4)$; decrease in the number of erythrocytes $(\mathrm{OR}=3.1)$; increase in the index of ATP-induced aggregation $(\mathrm{OR}=2.8)$; increase in the level of fibrinogen $(\mathrm{OR}=3.4)$, prolongation of APTT $(\mathrm{OR}=3.1)$; increase in the level of D-dimer $(\mathrm{OR}=1.3)$; increase in the level of homocysteine $(\mathrm{OR}=2.8)$; presence of minor allele $\mathrm{T}$ of polymorph locus $\mathrm{C} 148 \mathrm{~T}$ of $\beta$-fibrinogen gene $(\mathrm{OR}=4.2)$. The most significant among the analyzed parameters, according to our data, is the genetic conditionality - presence of minor allele $\mathrm{T}$ of polymorph locus C148T of $\beta$-fibrinogen gene. The abovementioned parameters may be predicting markers of ineffectiveness of assistive reproductive technologies among patients with psychosomatic disorders. Presence of prothrombotic conditions associated with APLS should be taken into account during the preparation for assistive reproductive technologies and correction must be made for them.

\section{References}

Bao, S. H., Sheng, S. L., Liao, H., Zhou, Q., Frempong, S. T., \& Tu, W. Y. (2017). Use of D-dimer measurement to guide anticoagulant treatment in recurrent pregnancy loss associated with antiphospholipid syndrome. American Journal of Reproductive Immunology, 78(6), e12770.

Boivin, J., \& Gameiro, S. (2015). Evolution of psychology and counseling in infertility. Fertility and Sterility, 104(2), 251-259.

Camilleri, R. S., Peebles, D., Portmann, C., Everington, T., \& Cohen, H. (2004). 455G/A $\beta$-fibrinogen gene polymorphism, factor $\mathrm{V}$ Leiden, prothrombin G20210A mutation and MTHFR C677T, and placental vascular complications. Blood Coagulation and Fibrinolysis, 15(2), 139-147.

Chan, W. S. (2009). The "ART" of thrombosis: A review of arterial and venous thrombosis in assisted reproductive technology. Current Opinion in Obstetrics and Gynecology, 21(3), 207-218.

Chernyshov, V., Dons'koi, B., \& Vodyanik, M. (2011). Anti-idiotypic regulation of cofactor-independent antiphospholipid antibodies. Central European Journal of Immunology, 36(4), 220-225.

Chighizola, C. B., Ubiali, T., \& Meroni, P. L. (2015). Treatment of thrombotic antiphospholipid syndrome: The rationale of current management - an insight into future approaches. Journal of Immunology Research, 2015, 1-20.

Coughlan, C., Walters, S., Ledger, W., \& Li, T. C. (2013). A comparison of psychological stress among women with and without reproductive failure. International Journal of Gynecology and Obstetrics, 124(2), 143-147.

Da Silva, F. F., Levy, R. A., \& de Carvalho, J. F. (2014). Cardiovascular risk factors in the antiphospholipid syndrome. Journal of Immunology Research, 2014, 1-6.

De Souza, A. W. S., Silva, N. P., de Carvalho, J. F., D’Almeida, V., Noguti, M. A. E., \& Sato, E. I. (2007). Impact of hypertension and hyperhomocyste- inemia on arterial thrombosis in primary antiphospholipid syndrome. Lupus, 16(10), 782-787.

Di Nisio, M., Rutjes, A. W. S., Ferrante, N., Tiboni, G. M., Cuccurullo, F., \& Porreca, E. (2011). Thrombophilia and outcomes of assisted reproduction technologies: A systematic review and meta-analysis. Blood, 118(10), 2670-2678.

Fabris, M., Cifü, A., Pistis, C., Siega-Ducaton, M., Fontana, D. E., Giacomello, R., Tonutti, E., \& Curcio, F. (2017). Exploring the plasmatic platelet-activating factor acetylhydrolase activity in patients with anti-phospholipid antibodies. Autoimmunity Highlights, 8(1).

Furness, D., Fenech, M., Dekker, G., Khong, T. Y., Roberts, C., \& Hague, W. (2011). Folate, vitamin B12, vitamin B6 and homocysteine: Impact on pregnancy outcome. Maternal and Child Nutrition, 9(2), 155-166.

Gómez-Puerta, J. A., \& Cervera, R. (2014). Diagnosis and classification of the antiphospholipid syndrome. Journal of Autoimmunity, 48-49, 20-25.

Ishihara, O., Adamson, G. D., Dyer, S., de Mouzon, J., Nygren, K. G., Sullivan, E. A., Zegers-Hochschild, F., \& Mansour, R. (2015). International Committee for Monitoring Assisted Reproductive Technologies: World report on assisted reproductive technologies, 2007. Fertility and Sterility, 103(2), 402-413.

Islam, M., Alam, F., Kamal, M., Wong, K., Sasongko, T., \& Gan, S. (2016). "Non-criteria" neurologic manifestations of antiphospholipid syndrome: A hidden kingdom to be discovered. CNS and Neurological Disorders - Drug Targets, 15(10), 1253-1265.

Jeddi-Tehrani, M., Torabi, R., Zarnani, A. H., Mohammadzadeh, A., Arefi, S., Zeraati, H., Akhondi, M. M., Chamani-Tabriz, L., Idali, F., Emami, S., \& Zarei, S. (2011). Analysis of plasminogen activator inhibitor-1, integrin beta3, beta fibrinogen, and methylenetetrahydrofolate reductase polymorphisms in Iranian women with recurrent pregnancy loss. American Journal of Reproductive Immunology, 66(2), 149-156.

Kasum, M., Danolić, D., Orešković, S., Ježek, D., Beketić-Orešković, L., \& Pekez, M. (2014). Thrombosis following ovarian hyperstimulation syndrome. Gynecological Endocrinology, 30(11), 764-768.

Lai, W. K. C., \& Kan, M. Y. (2015). Homocysteine-induced endothelial dysfunction. Annals of Nutrition and Metabolism, 67(1), 1-12.

Lampe, A., \& Schüßler, G. (2015). Psychosoziale Aspekte in der Fortpflanzungsmedizin / Psychosocial factors in reproductive medicine. Zeitschrift Für Psychosomatische Medizin Und Psychotherapie, 61(4), 309-326.

Levy, G., \& Lucidi, R. S. (2011). Thrombophilia and ovarian hyperstimulation syndrome: A case report. Hawaii Medical Journal, 70(5), 97-98.

Madjunkova, S., Volk, M., Peterlin, B., \& Plaseska-Karanfilska, D. (2012). Detection of thrombophilic mutations related to spontaneous abortions by a multiplex SNaPshot method. Genetic Testing and Molecular Biomarkers, 16(4), 259-264.

Mascarenhas, M. N., Flaxman, S. R., Boerma, T., Vanderpoel, S., \& Stevens, G. A. (2012). National, regional, and global trends in infertility prevalence since 1990: A systematic analysis of 277 health surveys. PLoS Medicine, 9(12), e1001356.

Mashkova, T. Y. (2015). Thrombophilia and failures of extracorporal fertilization. Obstetrics, Gynecology and Reproduction, 9(3), 17-21.

Masliah-Planchon, J., \& Darnige, L. (2012). Anticorps antiphospholipides et hémostase. La Revue de Médecine Interne, 33(4), 181-188.

Mehdi, A., Salti, I., \& Uthman, I. (2011). Antiphospholipid syndrome: Endocrinologic manifestations and organ involvement. Seminars in Thrombosis and Hemostasis, 37(1), 049-057.

Messerlian, C., \& Gaskins, A. J. (2017). Epidemiologic approaches for studying assisted reproductive technologies: Design, methods, analysis, and interpretation. Current Epidemiology Reports, 4(2), 124-132.

Morandi Aléssio, A., Siqueira, L. H., Couto de Carvalho, E. C., Barini, R., de Pádua Mansur, A., Fenalti Hoehr, N., \& Annichino-Bizzacchi, J. M. (2008). Estrogen receptor alpha and beta gene polymorphisms are not risk factors for recurrent miscarriage in a Brazilian population. Clinical and Applied Thrombosis/Hemostasis, 14(2), 180-185.

Negrini, S., Pappalardo, F., Murdaca, G., Indiveri, F., \& Puppo, F. (2016). The antiphospholipid syndrome: From pathophysiology to treatment. Clinical and Experimental Medicine, 17(3), 257-267.

Nelson, S. M. (2013). Venous thrombosis during assisted reproduction: Novel risk reduction strategies. Thrombosis Research, 131, S1-S3.

Oszajca, K., Wroński, K., Janiszewska, G., Bieńkiewicz, M., Panek, M., Bartkowiak, J., \& Szemraj, J. (2012). Association analysis of genetic polymorphisms of factor $\mathrm{V}$, factor VII and fibrinogen $\beta$ chain genes with human abdominal aortic aneurysm. Experimental and Therapeutic Medicine, 4(3), $514-518$.

Rao, A. K., Chitkara, U., \& Milki, A. A. (2005). Subclavian vein thrombosis following IVF and ovarian hyperstimulation: A case report. Human Reproduction, 20(12), 3307-3312.

Rova, K., Passmark, H., \& Lindqvist, P. G. (2012). Venous thromboembolism in relation to in vitro fertilization: An approach to determining the incidence and increase in risk in successful cycles. Fertility and Sterility, 97(1), 95-100. 
Rupert, J. L., Devine, D. V., Monsalve, M. V., \& Hochachka, P. W. (1999). Betafibrinogen allele frequencies in Peruvian Quechua, a high-altitude native population. American Journal of Physical Anthropology, 109(2), 181-186.

Saccone, G., Berghella, V., Maruotti, G. M., Ghi, T., Rizzo, G., Simonazzi, G., Rizzo, N., Facchinetti, F., Dall'Asta, A., Visentin, S., Sarno, L., Xodo, S., Bernabini, D., Monari, F., Roman, A., Eke, A. C., Hoxha, A., Ruffatti, A., Schuit, E., \& Martinelli, P. (2017). Antiphospholipid antibody profile based obstetric outcomes of primary antiphospholipid syndrome: The Pregnants study. American Journal of Obstetrics and Gynecology, 216(5), 525.e1-525.e12.

Sauer, R., Roussev, R., Jeyendran, R. S., \& Coulam, C. B. (2010). Prevalence of antiphospholipid antibodies among women experiencing unexplained infertility and recurrent implantation failure. Fertility and Sterility, 93(7), 2441-2443.

Sciascia, S., Sanna, G., Murru, V., Roccatello, D., Khamashta, M. A., \& Bertolaccini, M. L. (2013). GAPSS: The global anti-phospholipid syndrome score Rheumatology, 52(8), 1397-1403.

Sennström, M., Rova, K., Hellgren, M., Hjertberg, R., Nord, E., Thurn, L., \& Lindqvist, P. G. (2017). Thromboembolism and in vitro fertilization - A systematic review. Acta Obstetricia et Gynecologica Scandinavica, 96(9), 1045-1052.

Simon, A., \& Laufer, N. (2012). Repeated implantation failure: Clinical approach. Fertility and Sterility, 97(5), 1039-1043.

Stuleva, N. S., Khizroeva, D. K., Mashkova, T. Y., \& Abramyan, G. R. (2015). Circulation of antiphospholipid antibodies and IVF failures. Obstetrics, Gynecology and Reproduction, 9(3), 6-10.

Tatarchuk, T. F., Giulmamedova, I. D., Rossokha, Z. I., Zadoorozhnaia, T. D., \& Giulmamedova, E. I. (2015). Beremennost' i rody posle cikla VRT u pacientki s mutaciej gena receptora FSG, vtorichnoj amenoreej, gipoplaziej matki i narusheniem receptivnosti jendometrija [Pregnancy and childbirth after the ART cycle in a patient with a mutation of the FSH receptor gene, secondary amenorrhoea, uterine hypoplasia and impaired endometrial receptivity]. Reproductive Endocrinology, 6, 72-75 (in Russian).

Ticconi, C., Mancinelli, F., Gravina, P., Federici, G., Piccione, E., \& Bernardini, S. (2011). Beta-fibrinogen $\mathrm{G}-455 \mathrm{~A}$ polymorphisms and recurrent miscarriage. Gynecologic and Obstetric Investigation, 71(3), 198-201.

Van 't Hooft, F. M., von Bahr, S. J. F., Silveira, A., Iliadou, A., Eriksson, P., \& Hamsten, A. (1999). Two common, functional polymorphisms in the promoter region of the $\beta$-fibrinogen gene contribute to regulation of plasma fibrinogen concentration. Arteriosclerosis, Thrombosis, and Vascular Biology, 19(12), 3063-3070.

Wang, H.-Y., Song, Y., Qiao, J., Liu, P., \& Chi, H.-B. (2017). Antiphospholipid antibody titers and clinical outcomes in patients with recurrent miscarriage and antiphospholipid antibody syndrome: A prospective study. Chinese Medical Journal, 130(3), 267.

Yajnik, C. S., Chandak, G. R., Joglekar, C., Katre, P., Bhat, D. S., Singh, S. N., Janipalli, C. S., Refsum, H., Krishnaveni, G., Veena, S., Osmond, C., \& Fall, C. H. (2014). Maternal homocysteine in pregnancy and offspring birthweight: epidemiological associations and Mendelian randomization analysis. International Journal of Epidemiology, 43(5), 1487-1497.

Yelnik, C. M., Kozora, E., \& Appenzeller, S. (2016). Non-stroke central neurologic manifestations in antiphospholipid syndrome. Current Rheumatology Reports, 18(2). 